\title{
Some criteria of critical infrastructures stability
}

\author{
Andrey Volkov ${ }^{1}$, and Liubov Shilova ${ }^{1, *}$ \\ ${ }^{1}$ Moscow State University of Civil Engineering, 129337, 26, Yaroslavskoye Shosse, Moscow, \\ Russian Federation
}

\begin{abstract}
Critical Infrastructures (CIs) are complex systems with a set of individual elements, such as buildings and facilities, technological equipment and energy supply networks, engineering, technology and other communications. The system criteria of Critical Infrastructures stability and their threshold are shown in the paper. The main criterion of CIs protection is engineering and functional stability. And the special criteria are the next: the criterion of work safety; the criterion of environmental safety; the criterion of energy safety; the criterion of resource safety (resource using in CIs); the criterion of CIs' automation level; the criterion of technological equipment safety; the criterion of reliability of project design solution; the criterion of engineering systems reliability; the criterion of engineering safety; the criterion of explosion and fire safety. The algorithm for evaluation of Critical Infrastructures stability is formulated in this paper.
\end{abstract}

\section{Introduction}

For many years the basis for the development of standards and regulations of critical infrastructures stability was the concept of absolute security, which began on the dawn of the technological revolution [2]. The idea of absolute security concept is based on the strict regulatory approach and it is a logical analysis of possible initiating events of emergency situations at the facility. It helps to model the factors influencing at the facility and to develop a system of compulsory measures to reduce possible losses. The main advantage of the absolute security concept is the fact that over the time it has evolved and nowadays it includes statistics of accidents and their consequences. In addition, when we use this approach, the security measures are installed as required, and their implementation is supported legally, so their performance are easy to control. For example, if a set of measures for particular class facilities is made, it is believed that this facility is absolutely secure, but the reliability of the technical means is implemented and staff actions aren't always correct. So the adequacy of selected measures can be evaluated only by experience, because otherwise the concept of absolute security contradicts to probabilistic laws of nature.

Currently one more concept is used widely in the industrialized countries. It is the concept of acceptable risk.

\footnotetext{
*Corresponding author: ShilovaLA@mgsu.ru
} 
In foreign and Russian literature [2], as well as to the authors' research work, preference is given to the second probabilistic approach of acceptable risk. This concept helps to define a quantitative evaluation of risk level; to simulate ways of transition emergencies situations to accidents accompanied by affecting factors; to establish acceptable levels of risk and etc.

According to $[3,14]$ the authors consider that risk is a hazardous events measure which characterize the probability of arise accident or disaster and scale of their consequences. The probabilistic concept of acceptable risk bases on the evaluation of the security index. And the adequacy of the chosen measures can be estimated only by using this security index.

So it is necessary to develop some index, which can help us to make a clear conclusion about CIs stability level. In practice this index is called a criterion.

CIs are complex systems with a set of individual elements, such as buildings and facilities, technological equipment and energy supply networks, engineering, technology and other communications, so we have to make a system of criteria, which helps us to determine the composition of protected and secured working space for Cis $[6,7,16]$.

\section{Methodologies}

In our research work a criterion of CIs stability is a limit value of quantitative and qualitative indexes which characterizes state of CIs and the conditions of their operation.

The analysis of actual research works in the field of our study $[1,4,5,8-11,12,15,18]$ helps us to identify the main requirements for the criteria of CIs stability. They are the following:

- the criterion should be complete and reflect main types of security threats;

- the criterion should be consistent and integrated;

- the criterion should have a minimum dimension.

Than we use method of expert evaluation for determining main criteria of critical infrastructures stability. This method is a part of decision science, and there are two groups of expert evaluation. The first group is based on individual opinions of different experts, and the second group consists of the collective experts' opinion.

In our study the group of experts from different organizations was formed. They are:

- the specialists of Russian and foreign universities;

- the heads of fuel and energy complex enterprise;

- the specialists of EMERCOM of Russia and etc.

The stability of CIs is a complex notion, that's why we decide to divide stability of CIs for two types: engineering and functional. We formed list of 70 criteria which could characterize engineering and functional stability of CIs. Later we used a ranking method to determine the most important of them. The experts arranged all criteria in the descending order of properties characterized stability of CIs. At the end of the experiment we got 10 criteria. But these criteria characterize stability of CIs different, and later we determine what criterion is more important and calculate their specific weight. Specific weight of criterion of CIs stability is a number from 0 to 1 , which is proportional to its importance.

There is an algorithm of expert evaluation method in the fig.1. 


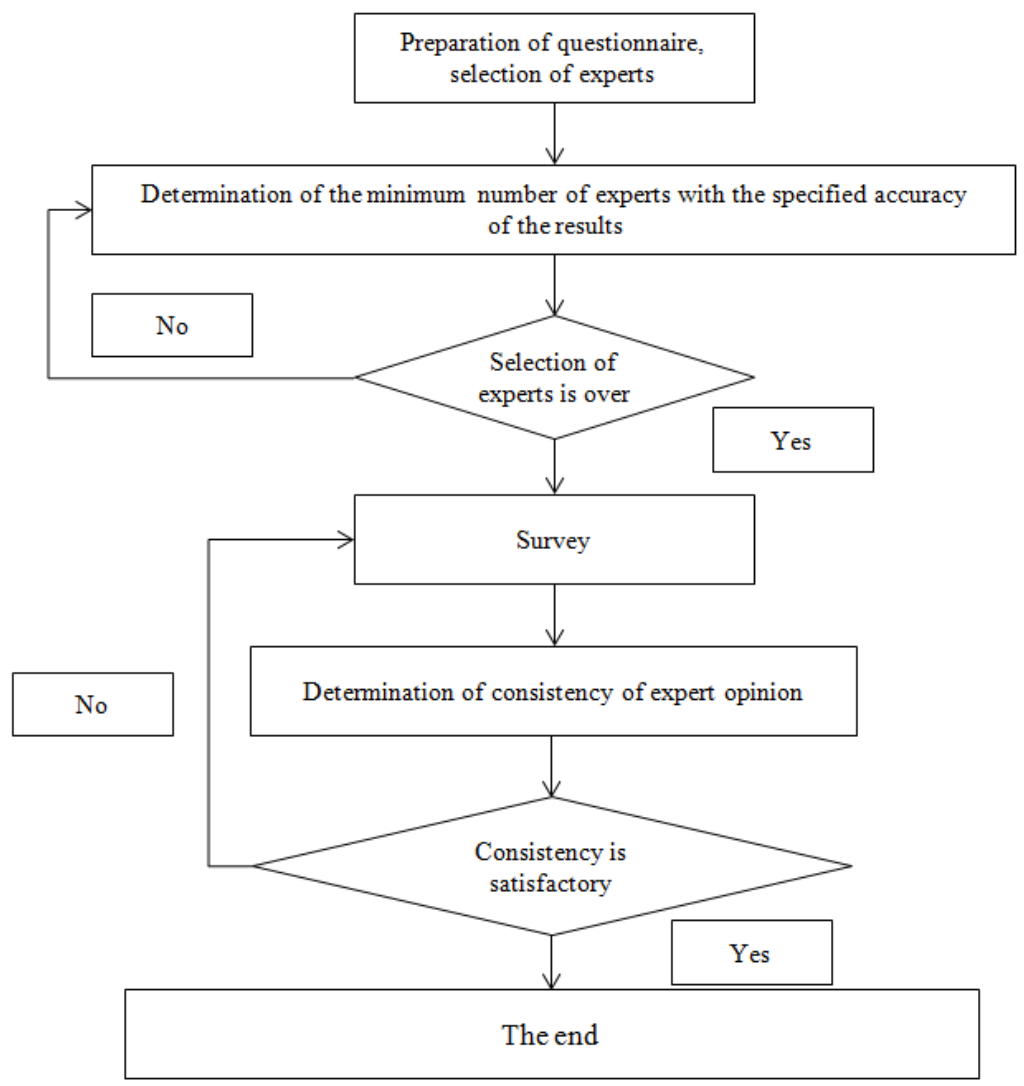

Fig. 1. An algorithm of expert evaluation method.

The number of experts can be determined through coefficient of mistake of expert analysis result, which lays in the range from 0 to 1 :

$$
\mathrm{n} \geq 0.5 *(0.33 / \mathrm{b}+5)
$$
result.

where $n$ is the number of experts; $b$ is the coefficient of mistake of expert analysis

When $b=10 \%, n \geq 0.5 *(0.33 / 0.1+5) \geq 4.15$, so there must be about 4 people in the expert group. The level of decision importance is very high, so we adopt the specified accuracy of the results about $95 \%, B=0.95$.

The minimum number of experts we can determine by next formula (2):

$$
N=\frac{B^{2} \cdot r_{a} \cdot r_{0}}{\Delta^{2}}=\frac{0.95^{2} * 0.95 * 0.05}{0.05^{2}}=17.1475
$$

where $r_{a}$ is the proportion of sample elements with the presence of the specified attribute; $r_{0}$ is the proportion of sample elements without the presence of the specified attribute; $\mathrm{B}$ is the accuracy of the results and $\Delta$ is a coverage error.

So the minimum number of experts is about 17 people.

In practice the minimum number of experts leads to unreliability opinion of the expert group, but maximum number of experts is not good too. In our research work we use next conventional formula for determination experts' number [17]: 


$$
n \approx \frac{m M_{0}\left(M_{0}-1\right)}{m M_{0}-\sum_{i=1}^{M_{0}} \mu(i)}+1
$$

where $M_{0}$ is the original number of experts; $m$ is the number of experts are called by each respondent.

In case when expert from the original number of experts calls the person who is not from this group, than $\mu=1$, otherwise ${ }^{\mu=0}$.

For determination of specific weight of criterion of CIs stability 15 people were invited and $M_{0}=15$. Each expert called some new experts, so we determined 12 more people. And the final number of experts became:

$$
M_{0}+\sum_{i=1}^{M_{0}} \mu(i)=15+12=27
$$

\section{Criteria of critical infrastructures stability}

According to the first stage of statistical research (statistical observation) and using statements of the official statistical government [13] we make three threshold values for each criterion.

The first threshold value is for normal state of CIs stability and it takes the value 1 .

The second threshold value is for potentially dangerous state of GIs stability. This value describes boundary state of CIs stability between normal and crisis and it takes value 0 .

The last one threshold value is for crisis state of CIs stability. It takes value "-1".

The main criterion of CIs protection is engineering and functional stability. And the special criteria are shown in the table 1.

\begin{tabular}{|c|c|c|c|}
\hline \multirow[t]{3}{*}{ № } & \multicolumn{3}{|c|}{ Threshold value } \\
\hline & «Crisis state of CIs stability» & $\begin{array}{l}\text { «Potentially dangerous } \\
\text { state of GIs stability » }\end{array}$ & $\begin{array}{c}\text { «Normal state of CIs } \\
\text { stability» }\end{array}$ \\
\hline & -1 & 0 & 1 \\
\hline \multicolumn{4}{|c|}{ Engineering stability } \\
\hline \multirow[t]{2}{*}{1.} & \multicolumn{3}{|c|}{ The criterion of explosion and fire safety } \\
\hline & $\begin{array}{l}\text { Constructions of CIs have the } \\
4^{\text {th }} \text { or the } 5^{\text {th }} \text { degree of fire } \\
\text { resistance. }\end{array}$ & $\begin{array}{c}\text { Constructions of CIs have } \\
\text { the } 3^{\text {th }} \text { degree of fire } \\
\text { resistance. }\end{array}$ & $\begin{array}{c}\text { Constructions of CIs } \\
\text { have the first or second } \\
\text { degree of fire resistance. }\end{array}$ \\
\hline \multirow[t]{2}{*}{2.} & \multicolumn{3}{|c|}{ The criterion of engineering safety } \\
\hline & $\begin{array}{c}\text { State of bearing structural } \\
\text { elements is emergency, state of } \\
\text { not bearing structural elements } \\
\text { is dilapidated }\end{array}$ & $\begin{array}{l}\text { All structural elements } \\
\text { must be repaired }\end{array}$ & $\begin{array}{l}\text { All structural elements } \\
\text { have some removable } \\
\text { defects }\end{array}$ \\
\hline \multirow[t]{2}{*}{3.} & \multicolumn{3}{|c|}{ The criterion of engineering systems reliability } \\
\hline & $\begin{array}{l}\text { Engineering systems have fatal } \\
\text { physical deterioration of }\end{array}$ & $\begin{array}{c}\text { Engineering systems have } \\
\text { disposable physical } \\
\text { deterioration }\end{array}$ & $\begin{array}{l}\text { Engineering systems are } \\
\text { new or renovated. }\end{array}$ \\
\hline \multirow[t]{2}{*}{4.} & \multicolumn{3}{|c|}{ The criterion of reliability of project design solution } \\
\hline & $\begin{array}{l}\text { Longevity of project design } \\
\text { solution is about } 20 \text { years }\end{array}$ & $\begin{array}{l}\text { Longevity of reliability of } \\
\text { project design solution is } \\
\text { about } 50 \text { years }\end{array}$ & $\begin{array}{l}\text { Longevity of reliability } \\
\text { of project design solution } \\
\text { is more than } 20 \text { years }\end{array}$ \\
\hline
\end{tabular}

Table 1. The criteria of critical infrastructures stability and their threshold value. 


\begin{tabular}{|c|c|c|c|}
\hline \multirow[t]{2}{*}{5.} & \multicolumn{3}{|c|}{ The criterion of technological equipment safety } \\
\hline & $\begin{array}{l}\text { Technological facilities have } \\
\text { fatal physical deterioration }\end{array}$ & $\begin{array}{c}\text { Technological facilities } \\
\text { have curable physical } \\
\text { deterioration }\end{array}$ & $\begin{array}{l}\text { Technological facilities } \\
\text { are new or renovated }\end{array}$ \\
\hline \multicolumn{4}{|c|}{ Functional stability } \\
\hline \multirow[t]{2}{*}{6.} & \multicolumn{3}{|c|}{ The criterion of CIs' automation level } \\
\hline & CIs are not automated & CIs are partly automated & CIs are automated \\
\hline \multirow[t]{2}{*}{7.} & \multicolumn{3}{|c|}{ The criterion of resource safety (resource using in CIs) } \\
\hline & $\begin{array}{l}\text { There are dangerous resources } \\
\text { (substances or materials) in } \\
\text { the CIs. Regulatory } \\
\text { requirements are not carried } \\
\text { out. } \\
\text {. }\end{array}$ & $\begin{array}{l}\text { There are dangerous } \\
\text { resources in the CIs, but all } \\
\text { regulatory requirements are } \\
\text { carried out. }\end{array}$ & $\begin{array}{l}\text { There are not dangerous } \\
\text { resources in the CIs }\end{array}$ \\
\hline \multirow[t]{2}{*}{8.} & \multicolumn{3}{|c|}{ The criterion of energy safety } \\
\hline & $\begin{array}{c}\text { There are any power supply } \\
\text { interruptions and no backup } \\
\text { power supply in the CIs. }\end{array}$ & $\begin{array}{l}\text { There are no power supply } \\
\text { interruptions and no backup } \\
\text { power supply in the CIs. }\end{array}$ & $\begin{array}{l}\text { There are backup power } \\
\text { supply and no power } \\
\text { supply interruptions and } \\
\text { no in the CIs. }\end{array}$ \\
\hline \multirow[t]{2}{*}{9.} & \multicolumn{3}{|c|}{ The criterion of environmental safety } \\
\hline & $\begin{array}{l}\text { The CIs generate waste of I, } \\
\text { IV hazard class during its } \\
\text { functionality. }\end{array}$ & $\begin{array}{l}\text { The CIs generate waste of } \\
\text { III hazard class during its } \\
\text { functionality. }\end{array}$ & $\begin{array}{l}\text { The CIs generate waste } \\
\text { of } \\
\text { IV, V hazard class during } \\
\text { its functionality. }\end{array}$ \\
\hline \multirow[t]{2}{*}{10} & \multicolumn{3}{|c|}{ The criterion of work safety } \\
\hline & $\begin{array}{c}\text { The requirements of GOST R } \\
54934-2012 / \text { OHSAS } \\
\text { 18001:2007 are not carried } \\
\text { out }\end{array}$ & $\begin{array}{c}\text { The requirements of GOST } \\
\text { R 54934-2012/OHSAS } \\
\text { 18001:2007 are carried out } \\
\text { partly }\end{array}$ & $\begin{array}{c}\text { The requirements of } \\
\text { GOST R 54934- } \\
\text { 2012/OHSAS } \\
\text { 18001:2007 are carried } \\
\text { out }\end{array}$ \\
\hline
\end{tabular}

There are values of specific weight for all criteria of CIs stability according to chosen methodology in the table 2 .

Table 2. The values of specific weight of CIs stability criteria.

\begin{tabular}{|c|c|c|c|}
\hline $\begin{array}{c}\text { The criterion of Cis } \\
\text { stability according to } \\
\text { table 1. }\end{array}$ & $\begin{array}{c}\text { Specific weight } \\
\text { of criterion }\end{array}$ & $\begin{array}{c}\text { The criterion of Cis } \\
\text { stability according to } \\
\text { table 1. }\end{array}$ & $\begin{array}{c}\text { Specific weight of } \\
\text { criterion }\end{array}$ \\
\hline 1 & 0.0816 & 6 & 0.0783 \\
\hline 2 & 0.1987 & 7 & 0.0870 \\
\hline 3 & 0.1493 & 8 & 0.0844 \\
\hline 4 & 0.0778 & 9 & 0.0734 \\
\hline 5 & 0.1111 & 10 & 0.0584 \\
\hline
\end{tabular}

\section{Discussions}

In our research work we try to determine some criteria, which can describe engineering and functional stability of CIs. But we have to understand that CIs are complex system. And after getting all information about our criteria we can't make an evaluation of engineering and functional stability of CIs without special formulas. So according to foreign experience we make next algorithm (5) for evaluation stability of CIs: 


$$
R_{\text {stab.i }}=\left\{\begin{array}{l}
N, \sum_{i=1}^{n} V_{i}^{N} \geq \delta_{N i} \\
P . D, \sum_{i=1}^{n} V_{i}^{P . D .} \prec \delta_{C i} \quad \text { and } \quad \sum_{i=1}^{n} V_{i}^{N} \prec \delta_{N i} \\
C, \sum_{i=1}^{n} V_{i}^{C} \geq \delta_{C i}
\end{array}\right.
$$

where $R_{\text {stab.i. }}$ is the evaluation of engineering or functional stability according to the criteria of CIs stability; $V_{i}^{N}, V_{i}^{C}$ are the specific weights of criteria, which numerical value is in the tolerance range of normal and crisis values; $\delta_{N i} \delta_{C i}$ are the coefficients that characterize the level of the normal and the crisis states of CIs.

If total weight of all criteria in the range of normal state is not less $\delta_{N i}$, the state of CIs stability is normal and $R_{\text {stab.i. }}=N$. In case when total weight of all criteria in the range of crisis state is $\delta_{C i}$ and more, then the state of CIs stability is critical and $R_{\text {stabi. }}=C$. In other cases $R_{\text {stab.i. }}=$ P.D.

The value of the normal state of CIs coefficient depends of the criteria's specific weights. And according to our study the coefficient for engineering stability $\left(\delta_{\text {Neng }}\right)$ is in the range from 0.348 to 0.6185 . The coefficient for functional stability $\left(\delta_{\text {Nfunc }}\right)$ is in the range from 0.1627 to 0.3815 . The value of the crisis state of GIs coefficient depends of the criteria's specific weights too and the coefficient for engineering stability $\left(\delta_{\text {ceng }}\right)$ is in the range from 0 to 0.1594 . The coefficient for functional stability $\left({ }^{\delta_{\text {cfinc }}}\right)$ is in the range from 0 to 0.1318 .

If we get other values for engineering and functional stability of CIs, than this CIs have potentially dangerous state.

\section{Conclusions}

In this paper we have studied the available tools for evaluation of CIs stability. To this end we have reviewed advantages and disadvantages of the concept of absolute security and the concept of acceptable risk. Moreover through an analysis of recent literature and according to expert evaluation method we have identified the main criteria of CIs stability.

But it is obviously that for different types of CIs we have to correct these criteria using calculated values and information which we can get during exploitation CIs. Future work should be devoted to developing optimal system of criteria of CIs stability according to types of CIs.

\section{References}

1. Z. Banschikova, V. Kamzolkin, V. Mitrofanov, TCS 2, 55-58 (2006)

2. Security of Russia. Risk analysis and security problems (2006)

3. G. Belyaev, I. Teterin, V. Yatsunenko, VTPU 5, 147-150 (2008)

4. A Volkov, HMSSU 3, 30-35 (2007)

5. A. Volkov, ICC 6, 34-35, (2000)

6. A. Volkov, IMFS, 133-160 (2004) 
7. A. Hussars, Proceedings of the II International Scientific and Practical Conference "Technical means of impending disaster", 27-36 (2006)

8. V. Durdenko, A. Rogozhin, HVIMIR 1, (2012)

9. S. Kondratiev, SS, 103-106 (2006)

10. M. Lyubimov, BMETXXI 8, 57-58 (2006)

11. B. Rodionov, Nanotechnology and integrated security BMETXXI 5, 60-63 (2009)

12. Y. Sdobnov, B. 4, 4 (2007)

13. Statistics: Textbook (2005)

14. F. Kadri, B. Birregah, E.Chatelet, JHSEM 11-2, 217-241 (2014)

15. A. Abbasi, N. JHSEM, 9-1(2012)

16. E. Casalicchio, M. Caselli, A. Coletta, I. Fovino, IJCI 9-1/2, 111-129 (2013)

17. Yu. Geraskin, Improving the efficiency of construction industry in the monolithic housing construction based on an evaluation of organizational and technological solutions (2004)

18. A. Ginzburg, S. Kachanov, IJAER 11(3), 1660-1665 (2016) 